American Journal of Applied Sciences 8 (6): 574-578, 2011

ISSN 1546-9239

(C) 2011 Science Publications

\title{
Optical and Physical Properties of Bismuth Borate Glasses Doped With Dy ${ }^{3+}$
}

\author{
${ }^{1}$ Smit Insiripong, ${ }^{2}$ Parnuwat Chimalawong, ${ }^{3,4}$ Jakrapong Kaewkhao and ${ }^{1,4}$ Pichet Limsuwan \\ ${ }^{1}$ Department of Physics, Faculty of Science, King Mongkut's \\ University of Technology Thonburi, 10140, Bangkok \\ ${ }^{2}$ Physics Program, Faculty of Science, Chandrakasem Rajabhat University, 10900, Bangkok \\ ${ }^{3}$ Center of Excellence in Glass Technology and Materials Science, \\ Nakhon Pathom Rajabhat University, 73000, Nakhon Pathom \\ ${ }^{4}$ Thailand Center of Excellence in Physics, CHE, Ministry of Education, \\ Bangkok 10400, Thailand
}

\begin{abstract}
This study reports on physical and optical properties of $\mathrm{Dy}^{3+}$ doped bismuth borate glass. The glasses containing $\mathrm{Dy}^{3+}$ in $(70-\mathrm{x}) \mathrm{B}_{2} \mathrm{O}_{3}: 30 \mathrm{Bi}_{2} \mathrm{O}_{3}: \mathrm{xDy}_{2} \mathrm{O}_{3}$ (where $\mathrm{x}=0.0-2.5 \mathrm{~mol} \%$ ) have been prepared by melt-quenching method. In order to understand the role of $\mathrm{Dy}_{2} \mathrm{O}_{3}$ in these glasses, the density, molar volume and optical spectra were investigated. The results show that molar volume of the glasses increase with the increasing of $\mathrm{Dy}_{2} \mathrm{O}_{3}$ concentration and consequently generating more non-bridging oxygen (NBOs) into glass matrix. The absorption spectra of $\mathrm{Dy}^{3+}$ doped in bismuth borate glass correspond with several bands, which are assigned from the ground state, ${ }^{6} \mathrm{H}_{15 / 2}$ to ${ }^{6} \mathrm{~F}_{3 / 2}(761 \mathrm{~nm}),{ }^{6} \mathrm{~F}_{5 / 2}(806 \mathrm{~nm}),{ }^{6} \mathrm{~F}_{7 / 2}(907$ $\mathrm{nm}),\left({ }^{6} \mathrm{H}_{7 / 2},{ }^{6} \mathrm{~F}_{9 / 2}\right)(1099 \mathrm{~nm}),\left({ }^{6} \mathrm{~F}_{11 / 2},{ }^{6} \mathrm{H}_{9 / 2}\right)(1283 \mathrm{~nm})$ and ${ }^{6} \mathrm{H}_{11 / 2}(1695 \mathrm{~nm})$. Moreover, the optical basicities were also theoretically determined.
\end{abstract}

Key words: Absorption spectra, optical basicity, Ultra Violet (UV), Rare-Earth ions (RE ${ }^{\mathrm{n}+}$ ), glass transition temperature, thermalization, bismuth, borate glass, luminescence, valent oxides, radiation, long infrared

\section{INTRODUCTION}

Glasses doped with Rare-Earth ions $\left(\mathrm{RE}^{\mathrm{n}+}\right)$ are proving to be luminescence materials as they have high emission efficiencies. These emissions correspond to $4 \mathrm{f}-4 \mathrm{f}$ and $4 \mathrm{f}-5 \mathrm{~d}$ electronic transitions in the $\mathrm{RE}^{\mathrm{n}+}$. The 4f-4f transition gives an especially sharp fluorescence pattern from the Ultra Violet (UV) to the infrared region. This is due to shielding effects of the outer $5 \mathrm{~s}$ and $5 \mathrm{p}$ orbitals on the $4 \mathrm{f}$ electrons. In recent years, glasses doped with rare-earth ions have drawn much attention due to their potential applications in solidstate lasers, optical amplifiers and three-dimensional displays (Malchukova et al., 2005; Vetrone et al., 2002; Biju et al., 2004; Lakshminarayana et al., 2009).

On the other hand, for higher valent oxides, such as $\mathrm{Bi}_{2} \mathrm{O}_{3}$ when used as a modifier, the cation produces important structural effects due to its highest valence. In the literature, it is supposed that $\mathrm{Bi}_{2} \mathrm{O}_{3}$ occupy both network-forming and network modifying positions. Therefore, the physical properties of such glasses exhibit discontinuous changes when the structural role of the cation switches over in this way (Baia et al., 2003). Also, glasses containing $\mathrm{Bi}_{2} \mathrm{O}_{3}$ have attracted a considerable attention because of their wide applications in the field of glass-ceramics, thermal and mechanical sensors, reflecting windows, radiation shielding and because they may be used as layers for optical and opto-electronic devices (Venkataraman and Varma, 2006). These glasses have a Long Infrared (IR) cut-off, which makes them ideal candidates for optical transmission (Bale et al., 2008). Bismuthate glasses containing alkali oxide act as ionic conductors and possess high conductivity compared to other heavy metal glasses (Gahlot et al., 2005). However, the study of the physical properties of the ionic glasses has been paid little attention.

$\mathrm{Dy}^{3+}\left(4 \mathrm{f}^{9}\right)$ doped glasses have been considered as promising laser active materials able to emit radiation associated with the ${ }^{6} \mathrm{H}_{13 / 2} \rightarrow{ }^{6} \mathrm{H}_{15 / 2}$ transition of $\mathrm{Dy}^{3+}$ ion around $3 \mu \mathrm{m}$ (Praveen a et al.,2008) .The active $\mathrm{Dy}^{3+}$ ion provides two typical emission transitions that correspond to ${ }^{4} \mathrm{~F}_{9 / 2} \rightarrow{ }^{6} \mathrm{H}_{15 / 2}$ (magnetic dipole) in blue $(\sim 480 \mathrm{~nm})$ and ${ }^{4} \mathrm{~F}_{9 / 2} \rightarrow{ }^{6} \mathrm{H}_{13 / 2}$ (electric dipole) in yellow

Corresponding Author: S. Insiripong, Department of Physics, Faculty of Science, King Mongkut's, University of Technology Thonburi, Bangkok 10140 Thailand 
Am. J. Applied Sci., 8 (6): 574-578, 2011

$(\sim 570 \mathrm{~nm})$ regions, which are also necessary for full primary color displays (Barkyoumb et al., 1997; Tanabe et al., 1998; Yu et al., 2002; Lakshminarayana et al., 2008).

In this study we report on optical, physical and structural properties of $\mathrm{Dy}^{3+}$ ion-doped bismuth borate glass in formula $(70-\mathrm{x}) \mathrm{B}_{2} \mathrm{O}_{3}: 30 \mathrm{Bi}_{2} \mathrm{O}_{3}: \mathrm{xDy}_{2} \mathrm{O}_{3}$ (where $\mathrm{x}$ $=0.0-2.5 \mathrm{~mol} \%$ ).

\section{MATERIALS AND METHODS}

Glass preparation: $\mathrm{Dy}^{3+}$ doped bismuth borate glasses with the following compositions (in mol\%) are developed for the present work along with a reference glass:

D0BB: $30.0 \mathrm{Bi}_{2} \mathrm{O}_{3}: 70 \mathrm{~B}_{2} \mathrm{O}_{3}$ (reference glass)

D05BB: $29.5 \mathrm{Bi}_{2} \mathrm{O}_{3}: 70 \mathrm{~B}_{2} \mathrm{O}_{3}: 0.5 \mathrm{Dy}_{2} \mathrm{O}_{3}$

D10BB: $29.0 \mathrm{Bi}_{2} \mathrm{O}_{3}: 70 \mathrm{~B}_{2} \mathrm{O}_{3}: 1.0 \mathrm{Dy}_{2} \mathrm{O}_{3}$

D15BB: $28.5 \mathrm{Bi}_{2} \mathrm{O}_{3}: 70 \mathrm{~B}_{2} \mathrm{O}_{3}: 1.5 \mathrm{Dy}_{2} \mathrm{O}_{3}$

D20BB: $28.0 \mathrm{Bi}_{2} \mathrm{O}_{3}: 70 \mathrm{~B}_{2} \mathrm{O}_{3}: 2.0 \mathrm{Dy}_{2} \mathrm{O}_{3}$

D25BB: $27.5 \mathrm{Bi}_{2} \mathrm{O}_{3}: 70 \mathrm{~B}_{2} \mathrm{O}_{3}: 2.5 \mathrm{Dy}_{2} \mathrm{O}_{3}$

All these glasses were prepared by using high purity grade of $\mathrm{Bi}_{2} \mathrm{O}_{3}$ (Fluka), $\mathrm{H}_{3} \mathrm{BO}_{3}$ (Fluka) and $\mathrm{Dy}_{2} \mathrm{O}_{3}$ (Fluka) as raw materials. Each batch weighing about $30 \mathrm{~g}$ was mixed homogeneously and melted at $1100^{\circ} \mathrm{C}$ for $3 \mathrm{~h}$ in an alumina crucible, in air. The melts were poured onto a preheat stainless steel plates. These glasses are in rectangular designs with a good transparency. All the glasses were annealed below the glass transition temperature to remove thermal strains. Finally, the as-prepared glass samples were cut and then finely polished to a dimension of $1.0 \times 2.0 \times 0.3 \mathrm{~cm}$ for properties investigation.

Measurements: By applying Archimedes principle, the weight of the prepared glass samples was measured in air and in xylene using a 4-digit sensitive microbalance (Denver, Pb214). Then, the density, $\rho$, was determined using the relation:

$\rho=\frac{\mathrm{W}_{\mathrm{a}}}{\mathrm{W}_{\mathrm{a}}-\mathrm{W}_{\mathrm{b}}} \times \rho_{\mathrm{b}}$

Where:

$\mathrm{W}_{\mathrm{a}}=$ The weight in air, $\mathrm{W}_{\mathrm{b}}$ is the weight in xylene

$\rho_{b}=$ The density of xylene $\left(\rho_{b}=0.863 \mathrm{~g} \mathrm{~cm}^{-3}\right)$

The corresponding molar volume $\left(\mathrm{V}_{\mathrm{M}}\right)$ was calculated using the relation, $V_{M}=M_{T} / \rho$, where $M_{T}$ is the total molecular weight of the multi-component glass system given by:
$\mathrm{M}_{\mathrm{T}}=\mathrm{x}_{\mathrm{Bi}_{2} \mathrm{O}_{3}} \mathrm{Z}_{\mathrm{Bi}_{2} \mathrm{O}_{3}}+\mathrm{x}_{\mathrm{B}_{2} \mathrm{O}_{3}} \mathrm{Z}_{\mathrm{B}_{2} \mathrm{O}_{3}}+\mathrm{x}_{\mathrm{Dy}_{2} \mathrm{O}_{3}} \mathrm{Z}_{\mathrm{Dy}_{2} \mathrm{O}_{3}}$

Where:

$$
\begin{aligned}
\mathrm{x}_{\mathrm{Bi}_{2} \mathrm{O}_{3}}, \mathrm{x}_{\mathrm{B}_{2} \mathrm{O}_{3}} \text { and } \mathrm{x}_{\mathrm{Dy}_{2} \mathrm{O}_{3}}= & \text { The mole fractions of the } \\
& \text { constituent oxides } \\
\mathrm{Z}_{\mathrm{Bi}_{2} \mathrm{O}_{3}}, \mathrm{Z}_{\mathrm{B}_{2} \mathrm{O}_{3}} \text { and } \mathrm{Z}_{\mathrm{Dy}_{2} \mathrm{O}_{3}}= & \text { The molecular weights of } \\
& \text { the constituent oxides }
\end{aligned}
$$

The optical absorption spectra were recorded at room temperature using a UV-visible-NIR spectrophotometer (Shimadzu, UV-3100), working in $190-2100 \mathrm{~nm}$.

\section{RESULTS}

Based on the determined density, the various physical properties of the glass studied are present in Table 1. Therefore, the Figs. 1-2 illustrate density and molar volume, respectively, as function of $\mathrm{Dy}_{2} \mathrm{O}_{3}$ concentration (\%mol). Figure 3 shows the typical absorption spectrum of bismuth borate glasses undoped and doped with $\mathrm{Dy}^{3+}$ 0.5-2.5\% mol.

Table 1: Density, molecular weight, molar volume and optical asicity of $(70-\mathrm{x}) \mathrm{B}_{2} \mathrm{O}_{3}: 30 \mathrm{Bi}_{2} \mathrm{O}_{3}: \mathrm{xDy}_{2} \mathrm{O}_{3}$ glass system

\begin{tabular}{lllll}
\hline $\begin{array}{l}\text { Percent } \\
\mathrm{Dy}_{2} \mathrm{O}_{3}\end{array}$ & $\begin{array}{l}\text { Density } \\
\left(\mathrm{g} \mathrm{cm}^{-3}\right)\end{array}$ & $\begin{array}{l}\mathrm{M}_{\mathrm{T}} \\
\left(\mathrm{g} \mathrm{mol}^{-1}\right)\end{array}$ & $\begin{array}{l}\mathrm{V}_{\mathrm{M}} \\
\left(\mathrm{cm}^{3} \mathrm{~mol}^{-1}\right)\end{array}$ & $\begin{array}{l}\text { Optical } \\
\text { basicity }\end{array}$ \\
\hline 0.000 & 4.206 & 190.387 & 45.261 & 0.6545 \\
0.500 & 4.166 & 191.904 & 46.064 & 0.6571 \\
1.000 & 4.184 & 193.421 & 46.228 & 0.6597 \\
1.500 & 4.176 & 194.938 & 46.675 & 0.6623 \\
2.000 & 4.203 & 196.455 & 46.747 & 0.6649 \\
2.500 & 4.193 & 197.972 & 47.210 & 0.6675 \\
\hline
\end{tabular}

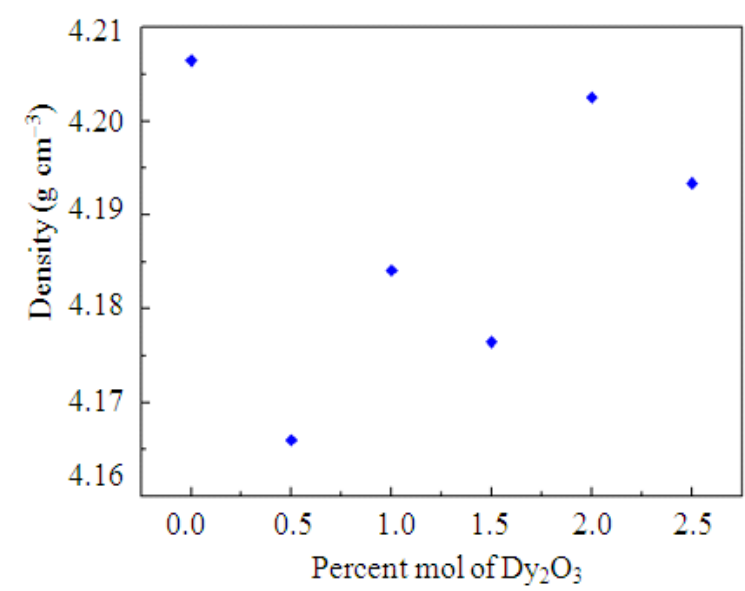

Fig. 1: Density of $(70-\mathrm{x}) \mathrm{B}_{2} \mathrm{O}_{3}: 30 \mathrm{Bi}_{2} \mathrm{O}_{3}: \mathrm{xDy}_{2} \mathrm{O}_{3}$ glass system 
Am. J. Applied Sci., 8 (6): 574-578, 2011

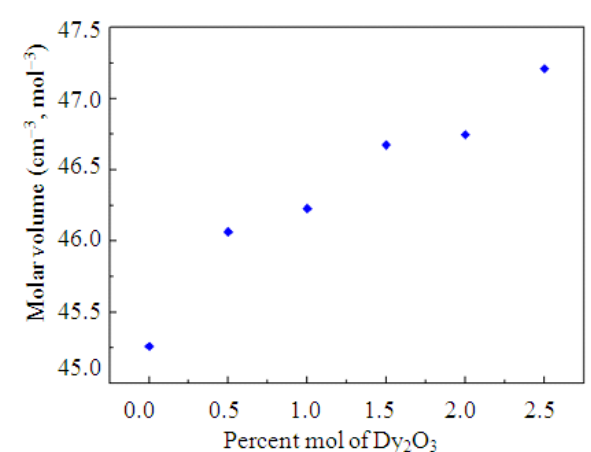

Fig. 2: Molar volume of $(70-\mathrm{x}) \mathrm{B}_{2} \mathrm{O}_{3}: 30 \mathrm{Bi}_{2} \mathrm{O}_{3}: \mathrm{xDy}_{2} \mathrm{O}_{3}$ glass system

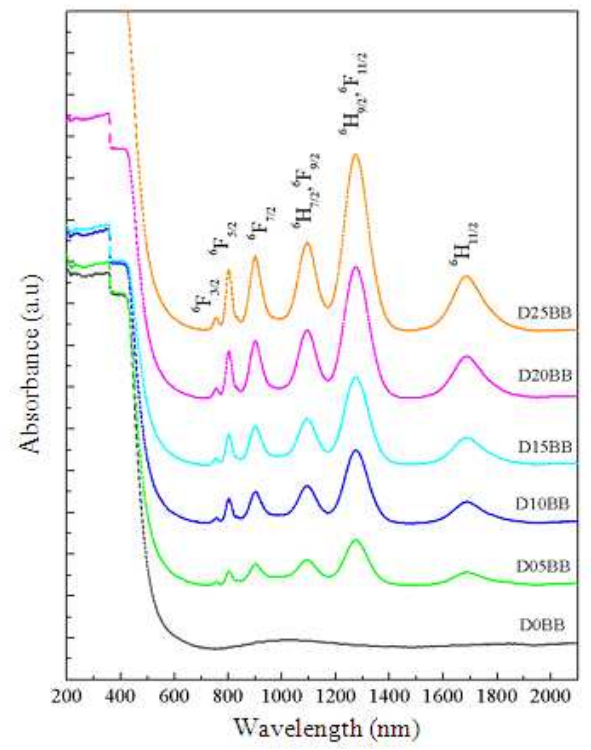

Fig. 3: Optical absorption spectra of (70x) $\mathrm{B}_{2} \mathrm{O}_{3}: 30 \mathrm{Bi}_{2} \mathrm{O}_{3}: \mathrm{xDy}_{2} \mathrm{O}_{3}$ glass system

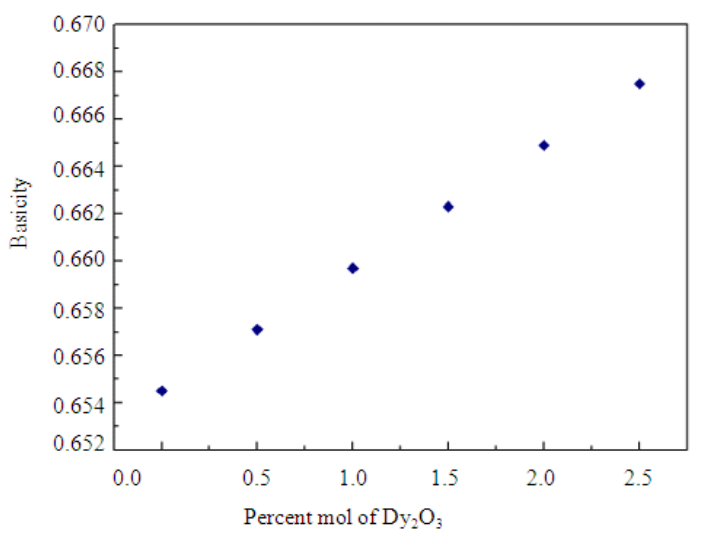

Fig. 4: Basicities of $(70-\mathrm{x}) \mathrm{B}_{2} \mathrm{O}_{3}: 30 \mathrm{Bi}_{2} \mathrm{O}_{3}: \mathrm{xDy}_{2} \mathrm{O}_{3}$ glass system
In multi-component oxide glasses, the theoretical basicity, $\Lambda_{\mathrm{th}}$, was calculated based on the basis of the equation given by:

$\Lambda_{\mathrm{th}}=\mathrm{x}_{1} \Lambda_{2}+\mathrm{x}_{2} \Lambda_{2}+\mathrm{x}_{3} \Lambda_{3}+\ldots$

Where:

$\Lambda_{1}, \Lambda_{2}$ and $\Lambda_{3}=$ Basicities of the oxide components $\mathrm{x}_{1}, \mathrm{x}_{2}$ and $\mathrm{x}_{3}=$ Their equivalent fractions (fraction of the total oxygen provided by the component oxide glass)

The optical basicity of the glass samples are evaluated and listed out in Table 1. Figure 4 illustrate optical basicity as a function of $\mathrm{Dy}_{2} \mathrm{O}_{3}$ concentration (\%mol).

\section{DISCUSSION}

Physical properties: From Fig. 1, although the relative molecular mass of $\mathrm{Dy}_{2} \mathrm{O}_{3}$ is higher than $\mathrm{B}_{2} \mathrm{O}_{3}$, density is found to not depend on $\mathrm{Dy}_{2} \mathrm{O}_{3}$ concentration. Boron oxide is well known conventional network former. It consists of a random three-dimensional network of 6membered boroxol rings (Suzuki et al., 2002), when some modifier is added, coordination number of boron atoms changes from 3 to 4 . As a result of this, NonBridging Oxygens (NBOs) would start to form. It is well reported that at low concentration of $\mathrm{Dy}_{2} \mathrm{O}_{3}$ acts as network modifier in place of network former in bismuth borate glass system. So, the increase in molar volume (Fig. 2) may indicate that the volume of NBO sites produced by the modifier $\mathrm{Dy}_{2} \mathrm{O}_{3}$.

Optical absorption: The optical absorption edges are not sharply defined in glass samples under study, in accordance with their amorphous nature (Chimalawong et al., 2010). It is observed that the absorption intensity of the observed bands increase with the increase of $\mathrm{Dy}_{2} \mathrm{O}_{3}$ concentration. From the Fig. 3, the spectra consist of various absorption levels corresponding to the transitions between the ground state and higher energy states. The bands are assigned from the ground state, ${ }^{6} \mathrm{H}_{15 / 2}$. The transitions from the next excited state ${ }^{6} \mathrm{H}_{13 / 2}$ may be ruled out due to thermalization as the energy gap between ${ }^{6} \mathrm{H}_{15 / 2}$ and ${ }^{6} \mathrm{H}_{13 / 2}$ is around 3000 $\mathrm{cm}^{-1}$. From this spectra, the levels of ${ }^{4} \mathrm{I}_{13 / 2},{ }^{4} \mathrm{~F}_{7 / 2},{ }^{4} \mathrm{G}_{11 / 2}$, ${ }^{4} \mathrm{I}_{15 / 2}$ are not observed. The absorption peaks at ${ }^{6} \mathrm{~F}_{3 / 2}(762$ $\mathrm{nm}),{ }^{6} \mathrm{~F}_{5 / 2}(805 \mathrm{~nm}),{ }^{6} \mathrm{~F}_{7 / 2}(905 \mathrm{~nm}),\left({ }^{6} \mathrm{H}_{7 / 2},{ }^{6} \mathrm{~F}_{9 / 2}\right)$ (1100 $\mathrm{nm}),\left({ }^{6} \mathrm{~F}_{11 / 2},{ }^{6} \mathrm{H}_{9 / 2}\right)(1280 \mathrm{~nm})$ and ${ }^{6} \mathrm{H}_{11 / 2}(1695 \mathrm{~nm})$ are observed and well resolved. The position and intensity of certain transitions of rare-earth ions are found to be very sensitive to the environment around the ion. Such 
transitions are termed as hypersensitive transitions (Jorgensen and Judd, 1964). All known hypersensitive transitions obey the selection rule $|\Delta \mathrm{S}|=0,|\Delta \mathrm{L}| \leq 2$, $|\Delta \mathrm{J}| \leq 2$ (Jorgensen and Judd, 1964). In the case of $\mathrm{Dy}^{3+}$ $\left({ }^{4} \mathrm{f}_{9}\right)$ ion, the hypersensitive transition $\left({ }^{6} \mathrm{~F}_{11 / 2} \rightarrow{ }^{6} \mathrm{H}_{9 / 2}\right)$ is found to be more intense than the other transitions.

Optical basicity: Theoretical optical basicity serves in the first approximation as a measure of the ability of oxygen to donate a negative charge in the glasses. The theoretical optical basicity can be used to classify the covalent/ionic ratios of the glasses since an increasing $\Lambda_{\text {th }}$ indicates decreasing covalency (Sindhu et al., 2007). In context of modification, therefore, we may note the following: modifier oxides should be more basic than the glass forming oxides. When modifier oxides are added to glass-forming oxides, the resulting modification reaction is like and acid-base reaction in which the sites in the acidic (glass forming) oxide are approached by the oxide ion (of the modifier) in the order of decreasing acidities. It is clearly observed from Fig. 4 that the optical basicity increases when $\mathrm{B}_{2} \mathrm{O}_{3}$ is replaced by one of the trivalent metal dysprosium oxide. The increase of optical basicity in this work means the higher ability of oxide ions to transfer electrons to the surrounding cations.

\section{CONCLUSION}

The $\mathrm{Dy}^{3+}$-doped bismuth borate glasses were prepared at various doping concentration of $\mathrm{Dy}_{2} \mathrm{O}_{3}$ and characterized for their physical and optical properties. The density and molar volume increase with increasing concentration of $\mathrm{Dy}_{2} \mathrm{O}_{3}$. The increase of molar volume with $\mathrm{Dy}_{2} \mathrm{O}_{3}$ content indicates that the extension of glass network due to the increase in the number of NBOs. The optical spectra were characterized using UV-VISNIR spectroscopy and show the six absorption bands in the range 190-2100 $\mathrm{nm}$. The rise of optical basicity in the present glasses indicates the higher ability of oxide ions to transfer electrons to the surrounding cations.

\section{ACKNOWLEDGEMENT}

P. Limsuwan would like to thanks King Mongkut's University of Technology Thonburi for partially funding under National Research University project. J. Kaewkhao would like to thanks Research and Development Institute, Nakhon Pathom Rajabhat University for facilities support.

\section{REFERENCES}

Baia, L. , R. Stefan, J. Popp, S. Simon and W. Kiefer, 2003. Vibrational spectroscopy of highly iron doped $\mathrm{B}_{2} \mathrm{O}_{3}-\mathrm{Bi}_{2} \mathrm{O}_{3}$ glass systems. J. NonCrystalline Solids, 324: 109-117. DOI: 10.1016/S0022-3093(03)00227-8

Bale, S., N.S. Rao and S. Rahman, 2008. Spectroscopic studies of $\mathrm{Bi}_{2} \mathrm{O}_{3}-\mathrm{Li}_{2} \mathrm{O}-\mathrm{ZnO}-\mathrm{B}_{2} \mathrm{O}_{3}$ glasses. Solid State Sci., 10: 326-331. DOI: 10.1016/j.solidstatesciences.2007.09.017

Barkyoumb, J.H., V.K. Mathur, A.C. Lewandowski, A. Tookey, P.D. Townsend and I. Giblin, 1997. Lowtemperature luminescence properties of $\mathrm{CaSO}_{4}: \mathrm{Dy}$. J. Lumin., 72-74: 629-632. PII: S0022 - 2313 (96) 00153-6

Biju, P.R., G. Jose, V. Thomas, V.P.N. Nampoori and N.V. Unnikrishnan, 2004. Energy transfer in $\mathrm{Sm}^{+}: \mathrm{Eu}^{+}$system in zinc sodium phosphate glasses. Opt. Mater., 24: 671-677. DOI: 10.1016/S0925-3467(03)00183-6

Chimalawong, P., J. Kaewkhao, C. Kedkaew and P. Limsuwan, 2010. Optical and electronic polarizability investigation of $\mathrm{Nd}^{3+}$ doped sodalime-silicate glasses. J. Phys. Chem. Solids, 71: 965-970. DOI: 10.1016/j.jpcs.2010.03.044

Gahlot, P.S., A. Agarwal, V.P. Seth, S. Sanghi, S.K. Gupta and M. Arora, 2005. Study of EPR, optical properties and electrical conductivity of vanadyl doped $\mathrm{Bi}_{2} \mathrm{O}_{3} \cdot \mathrm{PbO} \cdot \mathrm{B}_{2} \mathrm{O}_{3}$ glasses. Spectrochimica acta part a: Molecular and Biomolecular Spectroscopy, 61: 1189-1194. DOI: 10.1016/j.saa.2004.06.040

Jorgensen, C.K. and B.R. Judd, 1964. Hypersensitive pseudoquadrupole transitions in lanthanides. Mol. Phys., $\quad$ 8: 281- 290, DOI:10.1080/00268976400100321

Lakshminarayana, G., J. Qiu, M.G. Brik and I.V. Kityk, 2008. Photoluminescent of $\mathrm{Eu}^{3+}-, \mathrm{Tb}^{3+}-, \mathrm{Dy}^{3+}-$ and $\mathrm{Tm}^{3+}$ - doped transparent $\mathrm{GeO}_{2}-\mathrm{TiO}_{2}-\mathrm{K}_{2} \mathrm{O}$ glass ceramics. J. Phys. Condens. Matter, 20: 335106. DOI: 10.1088/0953-8984/20/33/335106

Lakshminarayana, G., R. Yang, M. Mao and J. Qiu, 2009. Spectral analysis of $\mathrm{RE}^{3+}(\mathrm{RE}=\mathrm{Sm}$, Dy and $\mathrm{Tm}$ ): $\mathrm{P}_{2} \mathrm{O}_{5}-\mathrm{Al}_{2} \mathrm{O}_{3}-\mathrm{Na}_{2} \mathrm{O}$ glasses. Opt. Mater., 31: 1506-1512. DOI: 10.1016/j.optmat.2009.02.010

Malchukova, E., B. Boizot, D. Ghaleb and G. Petite, 2005. Optical properties of pristine and $\gamma$-irradiated Sm doped borosilicate glasses. Nuclear Instru. Methods Phys. Res. A., 537: 411-414. DOI: 10.1016/j.nima.2004.08.054 
Praveena, R., R. Vijaya and C.K. Jayasankar, 2008. Photoluminescence and energy transfer studies of $\mathrm{Dy}^{3+}$-doped fluorophosphate glasses. Spectrochimica acta part a: Molecular and biomolecular spectroscopy, 70: 577-586. DOI: 10.1016/j.saa.2007.08.001

Sindhu, S., S. Sanghi, A. Agarwal, N. Kishore and V.P. Seth, 2007. Effect of $\mathrm{V}_{2} \mathrm{O}_{5}$ on structure and electrical properties of zinc borate glasses. J. Alloys Comp., 428: 206-213. DOI: 10.1016/j.jallcom.2006.01.110

Suzuki, T., M. Hirano and H. Hosono, 2002. Optical gaps of alkali borate and alkali fluoroborate glasses. J. Applied Phys., 91:4149-4153. DOI: 10.1063/1.1456946

Tanabe, S., J. Kang, T. Hanada and N. Soga, 1998. Yellow/blue luminescences of $\mathrm{Dy}^{3+}$-doped borate glasses and their anomalous temperature variations. J. Non-Cryst. Solids,. 239:170-175. PII: S0022 3093 (98) 00734 - 0
Venkataraman, B.H. and K.B.R. Varma, 2006. Electrical properties of $\mathrm{SrBi}_{2}\left(\mathrm{Nb}_{0.7} \mathrm{~V}_{0.3}\right)_{2} \mathrm{O}_{9-\delta}$ in the $\mathrm{SrO}-\mathrm{Bi}_{2} \mathrm{O}_{3}-0.7 \mathrm{Nb}_{2} \mathrm{O}_{5}-0.3 \mathrm{~V}_{2} \mathrm{O}_{5}-\mathrm{Li}_{2} \mathrm{~B}_{4} \mathrm{O}_{7}$ glass system. J. Non-Crystalline Solids, 352: 695-699. DOI:10.1016/j.jnoncrysol.2005.11.053

Vetrone, F., J.-C. Boyer, J.A. Capobianco, A. Speghini and M. Bettinelli2002. $980 \mathrm{~nm}$ excited upconversion in an Er-doped $\mathrm{ZnO}-\mathrm{TeO}_{2}$ glass. Appl. Phys. Lett., 80:1752-1754. DOI: 10.1063/1.1458073

Yu, M., J. Lin, J. Wang, J. Fu and S. Wang et al., 2002. Fabrication, patterning and optical properties of nanocrystalline $\mathrm{YVO}_{4}$ : $\mathrm{A}\left(\mathrm{A}=\mathrm{Eu}^{3+}, \mathrm{Dy}^{3+}, \mathrm{Sm}^{3+}\right.$, $\mathrm{Er}^{3+}$ ) phosphor films via sol-gel soft lithography. Chem. Mater., 14: 2224-2231. DOI: $10.1021 / \mathrm{cm} 011663 \mathrm{y}$ 